\title{
Associations between screen time, physical activity, and depressive symptoms during the 2019 coronavirus disease (COVID-19) outbreak among Chinese college students
}

Yi Zhang ${ }^{1,2,3 \dagger}$, Xiaoyan $\mathrm{Wu}^{1,2,3 \dagger}$, Shuman Tao ${ }^{1,2,4 \dagger}$, Shiyue $\mathrm{Li}^{5}$, Le Ma ${ }^{6}$, Yizhen Yư ${ }^{7}$, Guilong Sun ${ }^{8}$, Tingting Li ${ }^{3}$ and Fangbiao Tao ${ }^{1,2,3^{*}}$ (1)

\begin{abstract}
Background: The 2019 novel coronavirus disease (COVID-19) emerges in China, which spreads rapidly and becomes a public health emergency of international concern. Chinese government has promptly taken quarantine measures to block the transmission of the COVID-19, which may cause deleterious consequences on everyone's behaviors and psychological health. Few studies have examined the associations between behavioral and mental health in different endemic areas. This study aimed to describe screen time (ST), physical activity (PA), and depressive symptoms, as well as their associations among Chinese college students according to different epidemic areas.
\end{abstract}

Methods: The study design is cross-sectional using online survey, from 4 to 12 February 2020, 14,789 college students accomplished this online study, participants who did not complete the questionnaire were excluded, and finally this study included 11,787 college students from China.

Results: The average age of participants was $20.51 \pm 1.88$ years. $57.1 \%$ of the college students were male. In total, $25.9 \%$ of college students reported depression symptoms. ST $>4 \mathrm{~h}$ /day was positively correlated with depressive symptoms ( $\beta=0.48,95 \% \mathrm{Cl} 0.37-0.59$ ). COVID-19ST > $1 \mathrm{~h}$ /day was positively correlated with depressive symptoms ( $\beta$ $=0.54,95 \% \mathrm{Cl}$ 0.43-0.65), compared with COVID-19ST $\leq 0.5 \mathrm{~h} /$ day. Compared with PA $\geq 3$ day $/$ week, PA $<3$ day $/$ week was positively associated with depression symptoms ( $\beta=0.01,95 \% \mathrm{Cl} 0.008-0.012)$. Compared with low ST and high PA, there was an interaction association between high ST and low PA on depression ( $\beta=0.31,95 \% \mathrm{Cl} 0.26-0.36)$. Compared with low COVID-19ST and high PA, there was an interaction association between high COVID-19ST and low PA on depression ( $\beta=0.37,95 \% \mathrm{Cl} 0.32-0.43$ ). There were also current residence areas differences.

Conclusions: Our findings identified that high ST or low PA was positively associated with depressive symptoms independently, and there was also an interactive effect between ST and PA on depressive symptoms.

Keywords: Screen time, COVID-19ST, Physical activity, Depression, College students, COVID-19

*Correspondence: taofangbiao@126.com

${ }^{\dagger}$ Yi Zhang, Xiaoyan Wu and Shuman Tao contributed equally to this work.

${ }^{3} \mathrm{NHC}$ Key Laboratory of Study on Abnormal Gametes and Reproductive Tract, No. 81 Meishan Road, Hefei 230032, Anhui, China

Full list of author information is available at the end of the article

\section{Background}

In December 2019, COVID-19 confirmed cases first appeared in Wuhan, Hubei Province and quickly spread to many cities in China, has eventually become a public health emergency of international concern $[1,2]$. The Chinese government has implemented strict self- and original author(s) and the source, provide a link to the Creative Commons licence, and indicate if changes were made. The images or other third party material in this article are included in the article's Creative Commons licence, unless indicated otherwise in a credit line to the material. If material is not included in the article's Creative Commons licence and your intended use is not permitted by statutory regulation or exceeds the permitted use, you will need to obtain permission directly from the copyright holder. To view a copy of this licence, visit http://creativecommons.org/licenses/by/4.0/. The Creative Commons Public Domain Dedication waiver (http://creativeco mmons.org/publicdomain/zero/1.0/) applies to the data made available in this article, unless otherwise stated in a credit line to the data. 
forced-quarantine measure across the country to hinder the transmission of the COVID-19 [3]. During the longtime home confinement, people's life behaviors are likely to be changed largely, people's psychological health may also be greatly affected [4].

As the previous studies testified, long-term home confinement leads to daily activities changed, which including decreased physical activity (PA) and increased screen time (ST), aims to seek accurate and up-to-date COVID19 information in order to make informed decisions [5, 6]. In Xiang's study, children and adolescents' median time spent in PA decreased drastically, approximately 435 $\mathrm{min} /$ week decreased on average; frequency of physical inactivity extensively increased from 21.3 to $65.6 \%$ during COVID-19 epidemic [6]. Meanwhile, another recent study has reported that time spent in PA decreased by $2.30 \pm 4.60 \mathrm{~h} /$ week and screen time increased by 4.85 $\pm 2.40 \mathrm{~h}$ /day among adolescents during COVID-19 epidemic [7]. In summary, these data demonstrated PA levels have decreased and screen time has increased since the COVID-19 outbreak among children and adolescents $[6,7]$. The understanding of the effects of physical activity on mental health, therefore, has the potential to influence, in various aspects, the clinical practice of a psychologist or psychiatrist, on the one hand, as an auxiliary tool in the prevention and treatment of psychiatric diseases, and as a tool in the promotion of a more satisfactory quality of life, or on the other hand, as a cause of problems that require adequate diagnosis and effective treatment [8]. Previous research on screen time and mental health during COVID-19 has shown that excessive screen time is associated cardiovascular disease risk factors such as obesity, high blood pressure, and insulin resistance in youth [9] and high ST can cause various maladaptive psychophysiological responses, such as arousal of the central nervous system, and can also adversely association sleep patterns and intrapersonal social interactions [10,11].

As COVID-19 outbreak is sudden and widespread, the overload of epidemic information (disinformation and false reports) through media may have a huge impact on disaster and emergency communications, which can make people feel panic, anxiety, worry, and depressed [12, 13]. Furthermore, changes in life behavior may disrupt normal rhythm of life and then consequently increase their mental health problems $[14,15]$, which will have a profound impact on the public's mood and behavior during COVID-19 epidemic. In some longitudinal studies, adolescents maintaining regular physical activity (PA) showed an inverse association with psychosocial difficulties $[16,17]$. Meanwhile, emerging persuasive evidence have shown that beneficial mental health of sufficient PA and adverse mental effects of screen time among children and youth $[18,19]$. Compared to those who meet none or one movement behavior, children, and youth who meet all recommendations have better mental health [20].

Life behaviors have long been shown to play a role in the cause of chronic diseases, leading to suggestions for screen time, physical activity, and other behaviors among school-aged children and adults [21, 22]. However, there are few studies that investigate behavior changes among young adults during the COVID-19, as well as their effects on mental health among college students in different epidemic areas. Therefore, the present study first aims to describe the prevalence of ST, PA, and depressive symptoms among college students. Specifically, we also aim to evaluate the ST, PA, and depression symptoms in different epidemic areas. For these reasons, considering epidemic may well extend from weeks to months, drawing up an adapted physical training program and limited sedentary behaviors at home during the period of the epidemic, will decrease the negative psychological impact.

\section{Methods \\ Setting and participants}

This nationwide cross-sectional online survey was conducted during 4 to 12 February 2020. A two-stage sampling strategy was used: at the first stage, according to the geographic location and cooperation intention, 16 provinces or municipalities were selected: Wuhan City, neighboring provinces of Hubei (Henan, Anhui, Jiangxi, Hunan, Chongqing, and Shanxi), first-tier cities (Beijing and Shanghai), and other provinces (Jiangsu, Guangdong, Guangxi, Yunnan, Xingjiang, Heilongjiang and Jilin) (see Fig. 1). A total of 4 universities were randomly selected in Wuhan, Hubei, and 15 universities were randomly selected from other provinces or municipalities. At the second stage, 100-120 students from each grade (in general, 5 years for medical students and 4 years for nonmedical students) of a faculty were invited to participant online survey though Wenjuanxing platform (https:// www.wjx.cn/). In total, 14,789 students were selected; finally, after excluding the participants without completed questionnaires, 11,787 participants from 16 cities, 19 colleges in China were involved in the current study.

\section{Procedure}

They completed the questionnaires in Chinese college students through an online survey platform (Wenjuanxing platform). The Ethics Committee of Anhui Medical University approved this study (The number of the ethical approval is 20200319.). All respondents provided informed consent.

\section{Measurements}

The study included some questions related to the COVID-19 outbreak. The structured questionnaire 


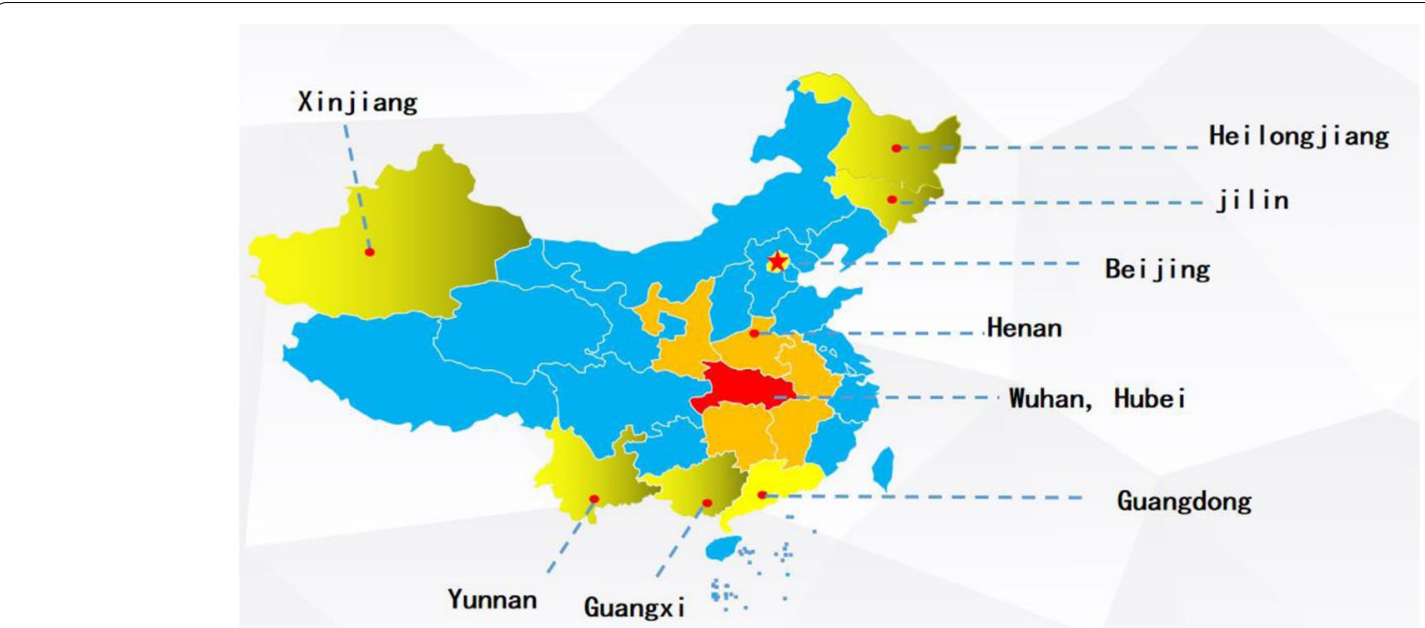

Fig. 1 The distribution of sample with the locations of the 16 provinces

consisted of questions that covered several aspects: (1) sociodemographic data (gender, age, grade, types of faculty, current residence area); (2) screen time (ST) and physical activity (PA), time spent on COVID-19 news on social media (COVID-19 ST); (3) depressive symptoms. ST was measured with one question: "How many hours per day did you spend on the computer (including playing video games or computer games or using a computer for something else) and watching TV/video programs during the past 7 days?" [20]. ST was categorized as $>4 \mathrm{~h} /$ day (high), $2-4 \mathrm{~h} /$ day (medium) and $\leq 2 \mathrm{~h} /$ day (low) [23-25]. COVID19ST was measured with one question: "How much time do you spend reading or watching COVID-19 on your phone, computer, or TV every day (COVID19 ST) during the past 7 days?". The PA of participants was measured with one question, "How many days have you been physical activity for at least one hour (60 $\mathrm{min}$ ) in the last week? (that is, the total amount of physical activity in a day that makes your heart beat faster and sometimes makes your breathing significantly faster)?" [26]. High PA was defined as at least 3 days per week ( $\mathrm{PA} \geq 3$ days) of exercise [27]. This item has been previously used in recognized student surveys such as the WHO's Health Behaviour in Schoolaged Children (HBSC) survey, and has been shown to produce valid and reliable responses [28].

Depressive symptoms were measured using the patient health questionnaire (PHQ) and calculations of scores were based on the previous study [29, 30]. The total stress subscale score was divided into normal (0-4), mild stress (5-9), moderate stress (10-14), severe stress (15-21) [31]. The questionnaire used in our study has previously been well validated [32].

\section{Statistical analysis}

Descriptive statistics of sociodemographic characteristics, screen time, physical activity were are presented as frequencies $(n)$ and percentages (\%). Chi-square test was used to analyze the detection rates of mild and moderate depression in general data, ST, COVID-19ST, and PA. The scores of the PHQ-9 scale were expressed as a dichotomous variable. To examine the interaction between PA, ST, and COVID-19ST on depression, we created a variable for the various combinations of PA and ST categories: high $\mathrm{PA}+$ low ST, high $\mathrm{PA}+$ high ST, and high PA + medium ST, low PA + low ST, low PA + high ST, and low PA + medium ST; and high PA + low COVID-19ST, high PA + high COVID-19ST, and high PA + medium COVID-19ST, low PA + low COVID-19ST, low PA + high COVID-19ST, and low PA + medium COVID19ST. We used linear regressions to examine the association between ST, COVID-19ST, physical activity, and the depression symptoms, with a significance level of $P$ $<0.05$. The associations are presented in odds ratios and their 95\% confidence intervals (CIs). Statistical analysis was performed using SPSS Statistic 23.0.

\section{Results}

\section{Characteristics of respondents}

Our study included 11,787 college students from 16 cities, 19 colleges in China. The demographic characteristics of college students were shown in Table 1 . Their mean age was $20.51 \pm 1.88$ years. $57.1 \%$ of the students were female. $25.9 \%(3053 / 11,787)$ students reported depressive symptoms, 31.3\% (187/597), 26.0\% (1,297/4,987), 22.7\% (243/1,070), and 25.8\% (1,326/5,133) in Wuhan area (Area 1), other cities in Hubei (Area 2), neighboring provinces of Hubei (Area 3), and other areas 
Table 1 Depression prevalence of college students with different demographic characteristics, n(\%)

\begin{tabular}{|c|c|c|c|c|c|c|c|}
\hline \multirow[t]{2}{*}{ Demographic variables } & \multirow[t]{2}{*}{ Total } & \multicolumn{5}{|l|}{ Depression } & \multirow[t]{2}{*}{$x^{2}$} \\
\hline & & Prevalence & Mild & Moderate & Moderate-severe & Severe & \\
\hline \multicolumn{8}{|l|}{ Gender } \\
\hline Male & $5056(42.9)$ & $1131(22.4)$ & $709(14.0)$ & 208(4.1) & 171(3.4) & $43(0.9)$ & \multirow[t]{2}{*}{$84.35^{* *}$} \\
\hline Female & $6731(57.1)$ & 1922(28.5) & 1313(19.5) & $361(5.4)$ & $171(2.5)$ & $77(1.1)$ & \\
\hline \multicolumn{8}{|l|}{ Residential areas } \\
\hline Rural & $5660(48.0)$ & $1431(25.3)$ & $942(16.6)$ & $286(5.1)$ & $153(2.7)$ & $50(0.9)$ & \multirow[t]{2}{*}{6.79} \\
\hline Urban & $6127(52.0)$ & $1622(26.4)$ & 1080(17.6) & 283(4.6) & 189(3.1) & $70(1.1)$ & \\
\hline \multicolumn{8}{|l|}{ Age (years) } \\
\hline$\leq 19$ & $3860(32.7)$ & $950(24.6)$ & $667(17.3)$ & $165(4.3)$ & $85(2.2)$ & $33(0.9)$ & \multirow[t]{3}{*}{$27.47^{* *}$} \\
\hline $20-22$ & $6426(54.5)$ & $1746(27.2)$ & $1116(17.4)$ & $333(5.2)$ & $224(3.5)$ & $73(1.1)$ & \\
\hline$\geq 23$ & $1501(12.7)$ & $357(23.8)$ & 239(15.9) & $71(4.7)$ & $33(2.2)$ & $14(0.9)$ & \\
\hline \multicolumn{8}{|l|}{ Current residence areas } \\
\hline Area 1 & $597(5.1)$ & 187(31.4) & 114(19.1) & $38(6.4)$ & 23(3.9) & $12(2.0)$ & \multirow[t]{4}{*}{$25.57^{*}$} \\
\hline Area 2 & $2237(19.0)$ & $579(25.9)$ & $409(18.3)$ & $97(4.3)$ & $61(2.7)$ & $12(0.5)$ & \\
\hline Area 3 & $2750(23.3)$ & $718(26.1)$ & $481(17.5)$ & 134(4.9) & $75(2.7)$ & $28(1.0)$ & \\
\hline Area 4 & $6203(52.6)$ & $1569(25.3)$ & 1018(16.4) & $300(4.8)$ & 183(3.0) & $68(1.1)$ & \\
\hline \multicolumn{8}{|l|}{ Type of faculty } \\
\hline Medical students & $5770(49.0)$ & 1338(19.2) & $898(15.6)$ & $255(4.4)$ & $134(2.3)$ & $51(0.9)$ & \multirow[t]{2}{*}{$46.87^{* *}$} \\
\hline Non-medical students & $6017(51.0)$ & $1715(28.5)$ & $1124(18.7)$ & $314(5.2)$ & $208(3.5)$ & $69(1.1)$ & \\
\hline \multicolumn{8}{|l|}{ Grade } \\
\hline Freshmen & $2930(24.9)$ & $708(24.2)$ & $484(16.5)$ & 134(4.6) & $67(2.3)$ & $23(0.8)$ & \multirow[t]{5}{*}{22.35} \\
\hline Sophomore & $2609(22.1)$ & $707(27.2)$ & $453(17.4)$ & $137(5.3)$ & $85(3.3)$ & $32(1.2)$ & \\
\hline Junior & $2667(22.6)$ & $724(27.1)$ & $481(18.0)$ & 123(4.6) & $91(3.4)$ & $29(1.1)$ & \\
\hline Senior & 2314(19.6) & $619(26.8)$ & $407(17.6)$ & $117(5.1)$ & $71(3.1)$ & $24(1.0)$ & \\
\hline Fifth-grade & $1267(10.7)$ & 295(23.2) & $197(15.5)$ & $58(4.6)$ & $28(2.2)$ & $12(0.9)$ & \\
\hline \multicolumn{8}{|l|}{ ST } \\
\hline$>4 \mathrm{~h}$ & $5570(47.3)$ & $1741(31.3)$ & $1126(20.2)$ & $349(6.3)$ & 195(3.5) & $71(1.3)$ & \multirow[t]{3}{*}{$196.15^{* *}$} \\
\hline $2-4 h$ & $3706(31.4)$ & $756(20.4)$ & $560(15.1)$ & 119(3.2) & $57(1.5)$ & $20(0.5)$ & \\
\hline$\leq 2 \mathrm{~h}$ & $2511(21.3)$ & $556(22.1)$ & $336(13.4)$ & $101(4.0)$ & $90(3.6)$ & $29(1.2)$ & \\
\hline \multicolumn{8}{|l|}{ COVID-19ST } \\
\hline$>1 \mathrm{~h}$ & 3933(33.4) & $1220(31.0)$ & $758(19.3)$ & $237(6.0)$ & $161(4.1)$ & $64(1.6)$ & \multirow[t]{3}{*}{$119.90^{* *}$} \\
\hline $0.5-1 \mathrm{~h}$ & $4623(39.2)$ & $1129(24.4)$ & $803(17.4)$ & $201(4.3)$ & $96(2.1)$ & $29(0.6)$ & \\
\hline$\leq 0.5 \mathrm{~h}$ & $3231(27.4)$ & $704(21.8)$ & $461(14.3)$ & $131(4.1)$ & $85(2.6)$ & $27(0.8)$ & \\
\hline \multicolumn{8}{|l|}{ PA } \\
\hline$\geq 3$ day & $3453(29.3)$ & $695(20.1)$ & $491(14.2)$ & $99(2.9)$ & $80(2.3)$ & $25(0.7)$ & \multirow[t]{2}{*}{$95.27^{* *}$} \\
\hline$<3$ day & $8334(70.7)$ & $2358(28.3)$ & 1531(18.4) & $470(5.6)$ & $262(3.1)$ & $95(1.1)$ & \\
\hline
\end{tabular}

Wuhan (Area 1), other cities in Hubei (Area 2), neighboring provinces of Hubei (Area 3), and other provinces (Area 4); PA physical activity, ST screen time ${ }^{*} P<0.05$

${ }^{* *} P<0.01$

(Area 4), respectively. Area 1 was statistically higher than other three areas $\left(\chi^{2}=25.57\right)$. The percentage of COVID$19 \mathrm{ST}>1 \mathrm{~h} /$ day, $0.5-1 \mathrm{~h} /$ day, and $\leq 0.5 \mathrm{~h} /$ day among college students were $33.4 \%, 39.2 \%, 27.4 \%$, and the PA $<3$ day/week and PA $\geq 3$ day/week accounted for $70.7 \%$ and 29.3\%. Higher rate of depressive symptoms was found in students who reported higher screen time $(\geq 4 \mathrm{~h}$ vs $2-4$ h mild: $20.2 \%$ vs $15.1 \%$, moderate: $6.3 \%$ vs $4.2 \%$, moderate-severe: $3.5 \%$ vs $1.5 \%$, severe: $1.3 \%$ vs $0.5 \% ; \chi^{2}$ $=196.15, P<0.001$ ); higher rate of depressive symptoms was found in students who reported higher screen time ( $\geq 1$ h vs $0.5-1$ h mild: $19.3 \%$ vs $17.4 \%$, moderate: $6.0 \%$ vs $4.3 \%$, moderate-severe: $4.1 \%$ vs $2.1 \%$, severe: $1.6 \%$ vs $0.6 \%$ ; $\chi^{2}=119.90, P<0.01$ ); or lower physical activity (mild $18.4 \%$ vs $14.2 \%$, moderate $5.6 \%$ vs $2.9 \%$, moderate-severe $3.1 \%$ vs $2.3 \%$, severe $1.1 \%$ vs $0.9 \%, X^{2}=95.27, P<0.001$ ). 
The rates of depressive symptoms were $31.3 \%, 20.3 \%$, $22.0 \%$ in ST $>4 \mathrm{~h} /$ day group, $2-4 \mathrm{~h} /$ day group, and $\leq 2 \mathrm{~h} /$ day group. The rates of depressive symptoms were $31.0 \%$, $24.4 \%$, and $21.8 \%$ in COVID-19ST $>1 \mathrm{~h}$ /day group, $0.5-1$ $\mathrm{h} /$ day group and $\leq 0.5 \mathrm{~h} /$ day group. Depressive symptoms accounts for $28.2 \%$ and $20.1 \%$ in PA $<3$ day/week group and $\mathrm{PA} \geq 3$ day/week group. These results were all showed in Table 1.

There were some differences between ST, PA, and demographic characteristics. Among gender, female students had higher ST who reported $>4 \mathrm{~h} /$ day $\left(\chi^{2}=\right.$ 225.13, $P<0.01)$, and had PA $<3$ day/week $\left(x^{2}=80.08\right.$, $P<0.01)$, had COVID-19ST $>1 \mathrm{~h} /$ day $\left(\chi^{2}=110.80, P<\right.$ $0.01)$. There were others demographic characteristics on ST and PA. However, there was no difference between current residence areas and ST, PA, but there was association between current residence areas and COVID19ST $\left(x^{2}=20.86, P<0.01\right)$. Other results were shown in Table 2.

\section{The correlation of screen time and physical activity with depression symptoms during COVID-19 outbreak}

In Table 3, after adjusting for confounding factors, compared with daily ST $\leq 2 \mathrm{~h}$ /day, ST $>4 \mathrm{~h}$ /day was positively correlated with depressive symptoms $(\beta=0.48$, 95\%CI 0.37-0.59). After adjusting for confounding factors, compared with daily COVID-19ST $\leq 0.5 \mathrm{~h} /$ day, COVID-19ST $>1 \mathrm{~h} /$ day was positively correlated with depressive symptoms $(\beta=0.54,95 \%$ CI $0.43-0.65)$. After adjusting for confounding factors, compared with PA $<3$ day/week, weekly PA $\geq 3$ day/week was positively correlated with depressive symptoms $(\beta=0.01,95 \% \mathrm{CI}$ 0.008-0.012). After adjusting for confounding factors, compared with low ST and high PA, higher ST and low PA were more likely to cause depressive symptoms $(\beta=$ 0.31, 95\%CI 0.26-0.36). After adjusting for confounding factors, compared with low COVID-19ST and high PA, higher COVID-19ST and low PA were more likely to cause depressive symptoms $(\beta=0.37,95 \% \mathrm{CI} 0.32-0.43)$.

\section{The relationship between screen time, physical activity, and depression symptoms among college students in different epidemic areas}

Table 4 showed the correlation between ST, PA, and depression symptoms in four different areas among college students. After adjusting for confounding factors, in different areas, ST and PA were significantly correlated with depression symptoms. Area 1: high ST $(\beta=1.265$, 95\%CI $0.72-1.81)$, low PA $(\beta=0.014$, 95\%CI $0.004-$ $0.025)$. Area 2: high ST $(\beta=0.69,95 \%$ CI $0.47-0.92)$; low PA $(\beta=0.009,95 \%$ CI $0.005-0.013)$; Area 3: high ST $(\beta=$ 0.20 , 95\%CI 0.15-0.42); low PA $(\beta=0.008$, 95\%CI $0.003-$ $0.012)$; Area 4 : high ST $(\beta=0.46,95 \%$ CI $0.31-0.61)$; low
PA $(\beta=0.011,95 \%$ CI $0.008-0.014)$. COVID19-ST was also had same results. They also had a multiplied interaction impact (ST and PA, COVID-19ST and PA) on depression symptoms. There were shown in Table 4.

\section{Discussion}

Our nationwide survey had some main findings. Firstly, nearly $50.0 \%$ of the college students ST were more than $4 \mathrm{~h}$ per day, $33.4 \%$ of the college students spent time on COVID-19ST, and 70.7\% of the college students had inadequate PA (PA < 3 day/week). Secondly, in our study, $25.9 \%$ of college students reported the depression symptoms. Among them, 31.3\%, 26.0\%, 22.7\%, and $25.8 \%$ of depression symptoms were found in Wuhan (Area 1), other cities in Hubei (Area 2), neighboring provinces of Hubei (Area 3), and other provinces (Area 4), respectively. Finally and interestingly, we also found the independent and interactive association between PA, ST, and depression symptoms in different epidemic area. To the best of our knowledge, this is the first large populationbased study examining media (screen time) and physical activity-related psychological impact during the epidemic outbreak among college students.

During COVID-19 epidemic, the present study find young adults spending $\geq 4 \mathrm{~h}$ per day in ST was $47.3 \%$, especially in Wuhan area (50.4\%), also during the epidemic, some researchers have demonstrated that ST was higher in adults, the mean ST was $264 \mathrm{~min} /$ day [5]; and one-third of community-based adults and health professionals spending $\geq 2 \mathrm{~h}$ per day in ST [33]. It also showed the extent to which the epidemic had hit people, and the results of college students were higher than previous study [27]. Most previous studies examined the ST exposure for other age-group, while our study focused on college students, who were more prone to susceptibility about "infodemic" [34]. Meantime, in our study, we find youths insufficient PA was nearly $71 \%$, which was higher than adults (nearly $60 \%$ ) during the epidemic [5], while the prevalence of insufficient physical activity was higher than previous study level (51\%) among college students [35].

The COVID-19 epidemic had caused serious threats to people's physical health and lives [36]. It has also triggered a wide variety of psychological problems, such as panic disorder, anxiety and depression $[12,13]$. The depression symptoms of this study were higher than the general survey of college students [37,38] and another cross-sectional epidemiological study [39]. Another study had reported that in a longer duration of quarantine, a high prevalence of invisible psychological pressure caused by screen time was positively correlated with depressive symptoms [40]. There results all demonstrated that the psychological impact of the epidemic cannot be 


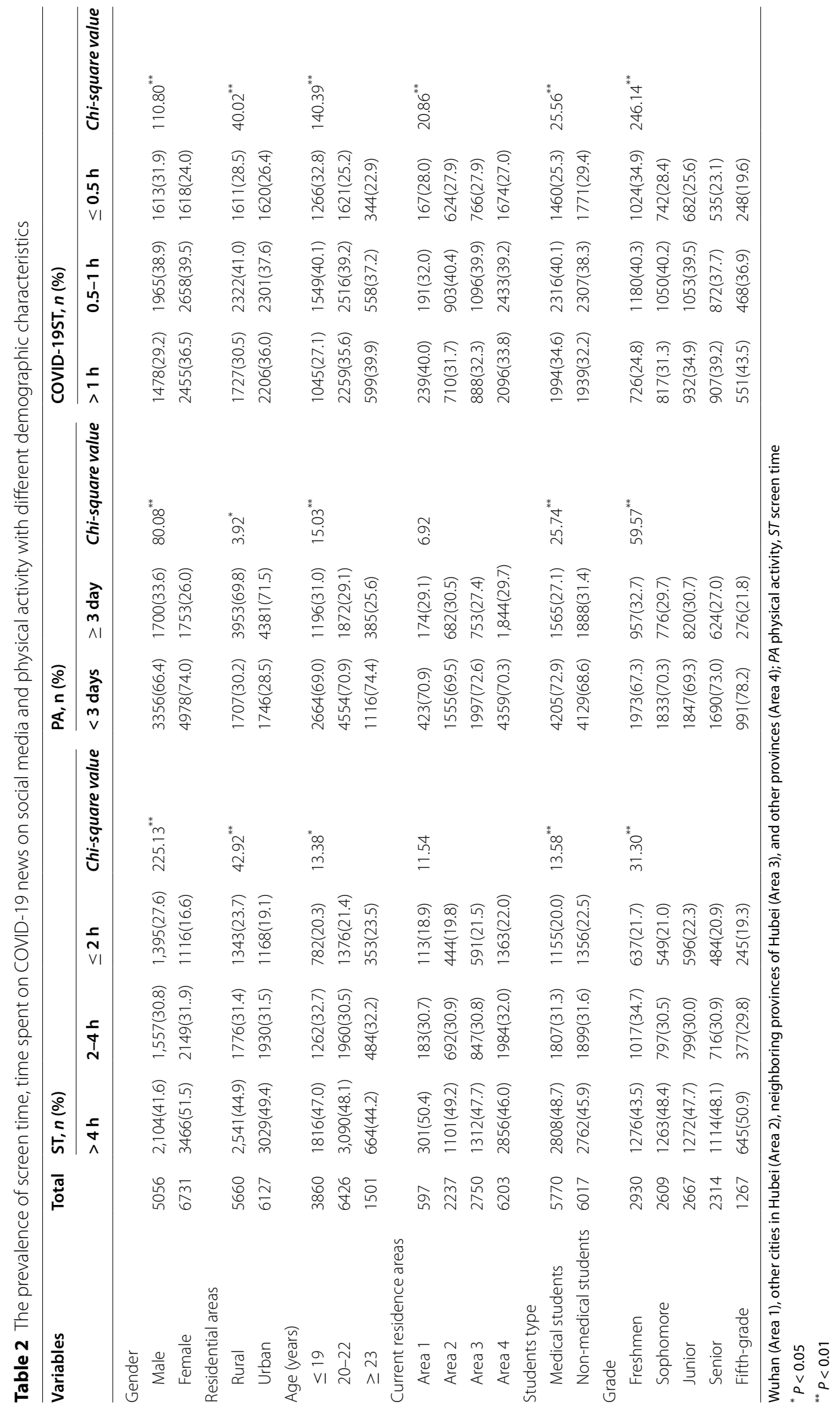


Table 3 The individual and interactive between screen time, COVID-19 screen time, physical activity, and depression among college students

\begin{tabular}{llll}
\hline $\begin{array}{l}\text { Different behavior } \\
\text { variables }\end{array}$ & \multicolumn{2}{l}{ Depression } \\
\cline { 2 - 4 } & $\boldsymbol{R}^{2}$ & $\boldsymbol{F}$ & $\boldsymbol{B}(\mathbf{9 5} \%)$ \\
\hline ST & 0.017 & 25.24 & $0.48(0.37,0.59)^{* *}$ \\
COVID-19ST & 0.018 & 27.43 & $0.54(0.43,0.65)^{* *}$ \\
PA & 0.018 & 27.05 & $0.01(0.008,0.012)^{*}$ \\
ST ${ }^{*}$ PA & 0.022 & 33.69 & $0.31(0.26,0.36)^{* *}$ \\
COVID-19ST*PA & 0.025 & 38.34 & $0.37(0.32,0.43)^{* *}$ \\
\hline
\end{tabular}

$P A$ physical activity, ST screen time

${ }^{*} P<0.05$

${ }^{* *} P<0.01$

Table 4 The individual and interactive between screen time, COVID-19 screen time, physical activity, and depression among college students in different epidemic areas

\begin{tabular}{|c|c|c|c|}
\hline \multirow[t]{2}{*}{ Different behavior variables } & \multicolumn{3}{|c|}{ Depression } \\
\hline & $\overline{R^{2}}$ & $F$ & $B(95 \%)$ \\
\hline \multicolumn{4}{|l|}{ Area1 } \\
\hline ST & 0.068 & 6.15 & $1.265(0.72,1.81)^{* *}$ \\
\hline COVID-19ST & 0.648 & 4.197 & $0.51(0.28,0.74)^{* *}$ \\
\hline PA & 0.048 & 4.198 & $0.014(0.004,0.025)^{*}$ \\
\hline$S T^{*} \mathrm{PA}$ & 0.065 & 5.82 & $0.54(0.29,0.79)^{* *}$ \\
\hline COVID-19ST*PA & 0.06 & 5.38 & $0.55(0.28,0.83)^{* *}$ \\
\hline \multicolumn{4}{|l|}{ Area2 } \\
\hline ST & 0.02 & 6.48 & $0.69(0.47,0.92)^{* *}$ \\
\hline COVID-19ST & 0.012 & 4.002 & $0.51(0.28,0.74)^{* *}$ \\
\hline PA & 0.012 & 8.743 & $0.009(0.005,0.013)^{*}$ \\
\hline$S T * P A$ & 0.021 & 6.983 & $0.33(0.23,0.44)^{* *}$ \\
\hline COVID-19ST*PA & 0.02 & 6.46 & $0.34(0.23,0.46)^{* *}$ \\
\hline \multicolumn{4}{|l|}{ Area3 } \\
\hline ST & 0.019 & 7.51 & $0.20(0.15,0.42)^{* *}$ \\
\hline COVID-19ST & 0.029 & 11.569 & $0.64(0.42,0.87)^{* *}$ \\
\hline PA & 0.022 & 8.743 & $0.008(0.003,0.012)^{*}$ \\
\hline$S T * P A$ & 0.023 & 9.042 & $0.20(0.096,0.31)^{*}$ \\
\hline COVID-19ST*PA & 0.025 & 22.58 & $0.35(0.30,0.45)^{* *}$ \\
\hline \multicolumn{4}{|l|}{ Area4 } \\
\hline ST & 0.016 & 14.16 & $0.46(0.31,0.61)^{* *}$ \\
\hline COVID-19ST & 0.016 & 14.32 & $0.48(0.33,0.63)^{* *}$ \\
\hline PA & 0.019 & 16.942 & $0.011(0.008,0.014)^{*}$ \\
\hline $\mathrm{ST}{ }^{*} \mathrm{PA}$ & 0.023 & 20.536 & $0.32(0.25,0.39)^{* *}$ \\
\hline COVID-19ST*PA & 0.025 & 22.58 & $0.37(0.30,0.45)^{* *}$ \\
\hline
\end{tabular}

$P A$ physical activity, ST screen time

${ }^{*} P<0.05$

${ }^{* *} P<0.01$ ignored, because in previous study, youths showed significantly higher rates of posttraumatic stress disorder (PTSD) symptoms because they have experienced quarantine [41]. The same results have been replicated in animal experiments. Even a brief duration (e.g., $24 \mathrm{~h}$ ) of isolation in adolescent rodents can cause increased anxiety [42], hyperactivity [43], and heightened sensitivity to social rewards [44], which extends to the seeking of food or drug rewards, making these animals particularly prone to developing addictions [45]. Specially, when rodent adolescent isolation occurs chronically, over 1 week or longer, it has even more profound effects [46]. Moreover, more attention should be paid to behaviors and the depression symptoms of females, non-medical background, and college students in Wuhan area. Females were more prone to high ST, low PA, and depression symptoms than males perhaps because women are more perceptual, emotional, relatively vulnerable to tension, and has high incidence of depression symptoms than men, as reported in the literature $[5,12,47,48]$.

The findings of this study suggested that high ST and low PA were significant positively correlated with depression symptoms individually and interactively. Some studies have also found high ST could cause positive relationships with anxiety and depression, so sedentary screen time among young adults are also significant factors to assess health behaviors $[49,50]$. During COVID19 , what we acquired information through social media (screen time) is sharply increased quantity but quality is uncontrolled; it is also accompanied by fragmented information $[51,52]$, and that is where the adverse emotion is also increased [51, 53, 54]. Fragmentation of information fragmentation of news will only lead to unnecessary trouble. Accumulating evidence suggest that screen time exposure of traumatizing or threatening content can influence fear conditioning by activating fear circuitry in the brain and can produce PTSD symptoms, especially flash backs [54]. Interestingly, we also found medium ST was negatively correlated with college students' depression symptoms, one possible reason was that in COVID-19 outbreak, many people are concerned with the COVID-19-related news and information including confirmed patients' information and their movements, precautionary measures about COVID-19 through media and Internet, which could be provided for online information, i.e., Ali Health, Ping An Good Doctor, Ding xiang yuan forum, WeChat implemented in China) and restored daily routines (i.e., online course, online working, exercise items on electronic devices) [33], and also suggested a U-shaped non-linear association between ST and depression symptoms [55]; appropriate information-seeking behaviors may reduce psychological health caused by uncertainty during COVID-19 epidemic [56], 
similarly, relative studies have also testified that to some extent, social media, for example engaging in directed communication (i.e., messaging), have been shown to increase well-being [57]; yet caution is warranted toward spending excessive time searching for COVID-19 news on screen time given the infodemic and emotional contagion through online social networks [33].

In additionally, increasing evidences were suggested that high PA was associated with numerous health benefits [58, 59], and also have positive effect during COVID-19 [60]. PA can influence the mental health of college students $[61,62]$. Lower physical activity led to more depression, which was consistent with the previous studies [27]. There were similar results between PA and depression symptoms during COVID-19 epidemic $[63,64]$. Associations between reduced depression symptoms, lower PA levels and increased ST in adolescents have been reported [65-68]. Previous studies concerned about people have higher depression symptoms who do not meet the recommendation $\mathrm{ST} \leq 2 \mathrm{~h} /$ day and weekly PA $>3$ days [66].

In our study, we also posed different ST and COVID19ST divisions, according to the special situation in COVID-19, we found that the interaction between ST $>4 \mathrm{~h} /$ day, weekly $\mathrm{PA}<3$ days and COVID-19ST $>1 \mathrm{~h} /$ day, weekly $\mathrm{PA}<3$ days were also correlated with higher depression symptoms. So our study suggested that high ST and low PA increase the risk of depression symptoms independently and also synergistically in college students. Some studies have suggested possible mechanisms: metabolic psychological health status 18) or social withdrawal [69]. Another explanation was that ST displaced PA [5, 70], which has proven to be protective against depressive and anxiety disorders [71, 72]. Especially in the case of public health emergencies, with the continuous influx of information (whether negative or positive), what is more, the negative information will be magnified, further influence PA, so the ST and PA behaviors of college students will be affected to different degrees, therefore cause unpredictable outcomes [5]. Some possible reasons were that high ST may displace their study and PA time, and then further infect their physical and psychosocial health [73-75], in a similar way, PA could buffer consequences of high screen time [76] and then further promote positive association of psychological well-being. It also named "displacement hypothesis" [73, 77, 78]. So, we should reasonably organize our time. Other study also demonstrated that maintaining opportunities for outdoor exercise and limiting screen time may promote better mental and general health during periods of confinement. In addition, taking into account different endemic areas, we can increase prevention and control and technical guidance to those areas.
We also explored the differences between screen time and physical activity of college students in different epidemic areas. The results showed that compared with college students in the other three areas, the higher ST and the lower PA in Area 1 college students, have higher the depression symptoms. The reasons may include that Area 1 students, considering that they live locally, will pay close attention to the situation of the outbreak, so they will have more screen time, which will lead to more depression symptoms. Also, due to the reason for home quarantine, physical activity was naturally decreased in four areas, especially in Area 1 [5]. In combination with the increase of screen time, physical activity would further increase the occurrence of depression.

\section{Strengths and limitation}

Our study also has some limitations. Firstly, the current study was a cross-sectional study, which could not build a causal relation between life behavior and psychological health outcomes. Furthermore, ST and PA were self-reported, considering special epidemic situations, we cannot actually test college students, so there may be a recall bias. Thirdly, the mechanism underlying the association was not directly assessed. Future longitudinal studies should further explore possible psychosocial and biological pathways. Finally, we had not obtain mental health conditions and life behaviors before the outbreak. Moreover, our study is a continuous follow-up study, which a follow-up investigation every 3 months will be conducted, thus enabling to further clarify the relationship.

Even though these limitations, our study also is also worthy to attention. Firstly, we have large samples and different epidemic areas to compare regional difference; therefore, local schools and governments can respond in time. Secondly, we timely grasp the epidemic problem, for domestic college students to provide some reference psychological research, especially the psychological factors. Thirdly, during the quarantine period, on the one hand, people should not only follow the news of the epidemic through the media, so as to further understand the current situation; finally, on the other hand, because of the quarantine, people's activities are greatly restricted, especially those who are in contact with the confirmed cases, and home quarantine will have different degrees of psychological impact. Therefore, our study took this as a starting point to conduct a nationwide survey on the mental health of college students.

\section{Conclusion}

Our findings identified that high ST and low PA exposure were positively associated with depression symptoms, and there was also an interactive effect. Compared 
with the emerging Wuhan City, other epidemic regions have lower risk of psychological health problems. In a major public health emergency like this, the media plays an important role in the society by providing authoritative information and social support and helping isolated individuals feel connected [79]. Relevant government departments should focus on the non-medical background of health education of college students by improving their awareness of COVID-19 [80, 81]. Physical activity is an important public health tool used in the treatment and prevention of various physical diseases, as well as in the treatment of some psychiatric diseases such as depressive and anxiety disorders [82]. Meanwhile, relevant government departments and universities should promote positive influence [83] to attract college students to reasonably arrange screen time and physical activity during the epidemic. Thus, during the epidemic, a better understanding of the association of PA, ST, and among college students will help school leaders and the Ministry of Education urgently identify and implement effective policies and interventions for college students [6]. COVID-19 as a pandemic is beyond the scope of the biomedical approach. It is a phenomenon that requires a biopsychosocial exploration as the factors influencing its proliferation and increased burden are multifaceted. The significance of our research is to provide an idea for teenagers to arrange their time reasonably when facing major public health emergencies (such as COVID-19), so as to deal with psychological problems during isolation and to establish ways for schools and government agencies to deal with public health events and prevent mental health. The significance of our research is to provide an idea for teenagers to arrange their time reasonably when facing major public health emergencies (such as COVID-19), so as to deal with psychological problems during isolation and to establish ways for schools and government agencies to deal with public health events and prevent mental health. Lack of PA and excessive ST were relevant to adiposity among rural Chinese adolescents [84] and social skill, which was one component of psychosocial wellbeing [85]. In addition, taking into account different endemic areas, we can increase prevention and control and technical guidance to those areas. Implementing a screen time and physical activity policy or national plan, establishing a public health screen time ad physical activity team, integrating screen time, and physical activity monitoring into school demographic health surveys and supporting multisectoral collaboration is a feasible and most cost-effective strategy to help the country move towards a more active and less sedentary population and society.

\section{Abbreviations}

ST: Screen time; PA: Physical activity; COVID-19: 2019 coronavirus disease; PHQ: Patient Health Questionnaire.

\section{Acknowledgements}

Thanks to all participants who were involved in the study for their inputs. The following researchers are not listed as authors: Heng Meng (Huazhong University of Science \& Technology), Hong Yan (Wuhan University), Jinkui Lu and Jianmin Xiang (Shangrao Normal University), Yan Zhang (contacts of Daqing Normal University, Guangxi University, Hohai University), Songli Mei (Jilin University), Asimuguli (Xinjiang Medical University), Xiaoming Lou (Zhengzhou University), Hong Wang (Chongqing Medical University), Lili Pan (Anhui Medical University), Zhaohui Huang (Anhui Medical University), Ying Huang (Kunming Medical University), Lianguo Fu (Bengbu Medical College), Yufeng Wen (Wannan Medical College), Wenjie Gong (Central South University), Jindong Ni (Guangdong Medical University), Yifei Hu (Capital Medical University), Xiaojian Yin (Shanghai Institute of Technology), and Chenwei Pan (Soochow University).

\section{Authors' contributions}

FT performed data collection and arrangement, YZ drafted the manuscript. ST, ZZ and XW was responsible for contacting cooperative units, participant recruitment and data collection. SL, LM,YY, GS, and TL were all responsible for participant recruitment and data collection. FT obtained the funding and designed the study. All authors have agreed to authorship and order of authorship for this manuscript.

\section{Funding}

The study is funded by supported by the Collaborative Innovation Project of Anhui Provincial Universities (GXXT-2020-068) and Anhui Medical University Emergency Key Research Project for Novel Coronavirus Pneumonia (YJGG202001). The funding bodies played no role in the design of the study and collection, analysis, and interpretation of data and in writing of the manuscript.

\section{Availability of data and materials}

The data used and analyzed during the study are available from the corresponding author on reasonable request.

\section{Declarations}

Ethics approval and consent to participate

Verbal informed consent was obtained from all participants in our manuscript. The Ethics Committee of Anhui Medical University approved this study.

\section{Consent for publication}

Not applicable.

\section{Competing interests}

The authors declare that they have no competing interests.

\section{Author details}

${ }^{1}$ Department of Maternal, Child and Adolescent Health, School of Public Health, Anhui Medical University, No. 81 Meishan Road, Hefei 230032, Anhui, China. ${ }^{2}$ MOE Key Laboratory of Population Health Across Life Cycle, No. 81 Meishan Road, Hefei 230032, Anhui, China. ${ }^{3}$ NHC Key Laboratory of Study on Abnormal Gametes and Reproductive Tract, No. 81 Meishan Road, Hefei 230032, Anhui, China. ${ }^{4}$ Department of Nephrology, The Second Hospital of Anhui Medical University, 678 Furong Road, Hefei 230601, Anhui, China. ${ }^{5}$ School of Health Sciences, Wuhan University, Wuhan 430071, Hubei, China. ${ }^{6}$ School of Public Health, Xi'an Jiaotong University Health Science Center, 76 Yanta West Road, Xi'an, China. ${ }^{7}$ Department of Maternal and Child Health, School of Public Health, Tongji Medical College, Huazhong University of Science \& Technology, Hangkong Road 13, Wuhan 430030, Hubei, China. ${ }^{8}$ SouthCentral Minzu University, 182 Minyuan Road, Wuhan 430074, Hubei, China.

Received: 3 June 2021 Accepted: 27 September 2021

Published online: 02 November 2021 


\section{References}

1. Hui DS, Azhar El, Madani TA, Ntoumi F, Kock R, Dar O, et al. The continuing 2019-nCoV epidemic threat of novel coronaviruses to global health-The latest 2019 novel coronavirus outbreak in Wuhan, China. Int J Infect Dis. 2020;93(91):264-6. https://doi.org/10.1016/j.jijid.2020.01.009.

2. World Health Organization. Novel coronavirus (2019-nCoV) situation report-17[EB/ OL] [2020.2.6]. 2020. https://www.who.int/docs/defaultsou rce/coronaviruse/situation-reports/20200206-sitrep-17-ncov.pdf?sfvrsn= $17 f 0 d c a$

3. Wilder-Smith A, Freedman DO. Isolation, quarantine, social distancing and community containment: pivotal role for old-style public health measures in the novel coronavirus (2019-nCoV) outbreak. J Travel Med. 2020;27(2):taaa020. https://doi.org/10.1093/jtm/taaa020.

4. Brooks SK, Webster RK, Smith LE, Woodland L, Wessely S, Greenberg N, et al. The psychological impact of quarantine and how to reduce it: rapid review of the evidence. Lancet. 2020;395(10227):912-20. https://doi.org/ 10.1016/S0140-6736(20)30460-8.

5. Qin F, Song YQ, Nassis GP, Zhao LN, Cui SQ, Lai LL, Wu ZZ, Xu MX, Qu CY, Dong YN, Wang ZW, Geng X, Zhao CC, Feng YW, Han ZN, Fan ZZ, Zhao JX. Prevalence of Insufficient physical activity, sedentary screen time and emotional well-Being during the early days of the 2019 Novel Coronavirus (COVID-19) outbreak in China: A national cross-sectional study (3/31/2020). Available at SSRN: https://ssrn.com/abstract $=3566176$ or doi:https://doi.org/10.2139/ssrn.3566176

6. Xiang M, Zhang Z, Kuwahara K. Impact of COVID-19 pandemic on children and adolescents' lifestyle behavior larger than expected. Prog Cardiovasc Dis. 2020a;63(4):531-2. https://doi.org/10.1016/j.pcad.2020.04. 013.

7. Pietrobelli A, Pecoraro L, Ferruzzi A, Heo M, Faith M, Zoller T, et al. Effects of COVID-19 lockdown on lifestyle behaviors in children with obesity living in Verona, Italy: a longitudinal study. Obesity. 2020;30. https://doi.org/ 10.1002/oby.22861.

8. Peluso MA, Guerra de Andrade LH. Physical activity and mental health: the association between exercise and mood. Clinics. 2005a;60(1):61-70. https://doi.org/10.1590/s1807-59322005000100012.

9. Nagata JM, Abdel Magid HS, Pettee Gabriel K. Screen time for children and adolescents during the coronavirus disease 2019 pandemic. Obesity. 2020;28(9):1582-3. https://doi.org/10.1002/oby.22917.

10. LeBourgeois MK, Hale L, Chang AM, Akacem LD, Montgomery-Downs HE, Buxton OM. Digital media and sleep in childhood and adolescence. Pediatrics. 2017;140(Suppl 2):S92-6.

11. Twenge JM, Martin GN, Campbell WK. Decreases in psychological wellbeing among American adolescents after 2012 and links to screen time during the rise of smartphone technology. Emotion. 2018;18(6):765-80.

12. Wang CY, Pan RY, Wan XY, Tan YL, Xu LK, Ho CS, et al. Immediate psychological responses and associated factors during the initial stage of the 2019 coronavirus disease (COVID-19) epidemic among the general population in China. Int J Environ Res Public Health. 2020;17:1729. https://doi. org/10.3390/ijerph17051729.

13. Zandifar A, Badrfam R. Iranian mental health during the COVID-19 epidemic. Asian J Psychiatr. 2020;51:101990. https://doi.org/10.1016/j.ajp. 2020.101990

14. Xiao C. A novel approach of consultation on 2019 novel coronavirus (COVID-19)-related psychological and mental problems: structured letter therapy. Psychiatry Investig. 2020;17(2):175-6. https://doi.org/10.30773/ pi.2020.0047.

15. Xiang Y-T, Yang Y, Li W, Zhang L, Zhang Q, Cheung T, et al. Timely mental health care for the 2019 novel coronavirus outbreak is urgently needed. Lancet Psychiatry. 2020b;7(3):228-9. https://doi.org/10.1016/S22150366(20)30046-8.

16. Sund AM, Larsson B, Wichstrøm L. Role of physical and sedentary activities in the development of depressive symptoms in early adolescence. Soc Psychiatry Psychiatr Epidemiol. 2011;46(5):431-41. https://doi.org/10. 1007/s00127-010-0208-0.

17. White K, Kendrick T, Yardley L. Change in self-esteem, self-efficacy and the mood dimensions of depression as potential mediators of the physical activity and depression relationship: exploring the temporal relation of change. Ment Health Phys Act. 2009;2:44-52. https://doi.org/10.1016/j. mhpa.2009.03.001.
18. Janssen I, Leblanc AG. Systematic review of the health benefits of physical activity and fitness in school-aged children and youth. Int J Behav Nutr Phys Act. 2010;7:40. https://doi.org/10.1186/1479-5868-7-40.

19. Tremblay MS, LeBlanc AG, Kho ME, Saunders TJ, Larouche R, Colley RC, et al. Systematic review of sedentary behaviour and health indicators in school-aged children and youth. Int J Behav Nutr Phys Act. 2011a;8:98. https://doi.org/10.1186/1479-5868-8-98.

20. Tremblay MS, LeBlanc AG, Kho ME, Saunders TJ, Larouche R, Colley RC, et al. Systematic review of sedentary behaviour and health indicators in school-aged children and youth. Int J Behav Nutr Phys Act. 2011 b;8:98. https://doi.org/10.1186/1479-5868-8-98.

21. Capodaglio EM. Attività fisica, strumento di prevenzione e gestione delle malattie croniche [Physical activity, tool for the prevention and management of chronic diseases]. G Ital Med Lav Ergon. 2018;40(2):106-19.

22. Cunningham C, O'Sullivan R, Caserotti P, Tully MA. Consequences of physical inactivity in older adults: A systematic review of reviews and meta-analyses. Scand J Med Sci Sports. 2020;30(5):816-27. https://doi. org/10.1111/sms.13616.

23. Sisson SB, Camhi SM, Church TS, Martin CK, Tudor-Locke C, Bouchard C, et al. Leisure time sedentary behavior, occupational/domestic physical activity, and metabolic syndrome in U.S. men and women. Metab Synd Relat Disord. 2009;7(6):529-36. https://doi.org/10.1089/met.2009.0023.

24. Sloan RA, Sawada SS, Girdano D, Liu YT, Biddle SJ, Blair SN. Associations of sedentary behavior and physical activity with psychological distress: a cross-sectional study from Singapore. BMC Public Health. 2013;13:885 https://doi.org/10.1186/1471-2458-13-885.

25. Hamer M, Stamatakis E, Mishra GD. Television- and screen-based activity and mental well-being in adults. Am J Prev Med. 2010;38(4):375-80 https://doi.org/10.1016/j.amepre.2009.12.030.

26. Tremblay MS, Warburton DE, Janssen I, Paterson DH, Latimer AE, Rhodes RE, et al. New Canadian physical activity guidelines. Appl Physiol Nutr Metab. 2011c;36(1):36-46; 47-58. https://doi.org/10.1139/H11-009.

27. Wu XY, Tao SM, Zhang YK, Zhang SC, Tao FB. Low physical activity and high screen time can increase the risks of mental health problems and poor sleep quality among Chinese college students. PLoS One. 2015;10(3):e0119607. https://doi.org/10.1371/journal.pone.0119607.

28. Janssen I, Katzmarzyk PT, Boyce WF, Vereecken C, Mulvihill C, Roberts C, et al. Health behaviour in school-aged children obesity working group. Comparison of overweight and obesity prevalence in school-aged youth from 34 countries and their relationships with physical activity and dietary patterns. Obes Rev. 2005;6(2):123-32. https://doi.org/10.1111/j. 1467-789X.2005.00176.x.

29. Martin A, Rief W, Klaiberg A, Braehler E. Validity of the brief patient health questionnaire mood scale (PHQ-9) in the general population. Gen Hosp Psychiatry. 2006;28(1):71-7. https://doi.org/10.1016/j.genhosppsych.2005. 07.003.

30. Beard C, Hsu KJ, Rifkin LS, Busch AB, Björgvinsson T. Validation of the PHQ-9 in a psychiatric sample. J Affect Disord. 2016;193:267-73. https:// doi.org/10.1016/j.jad.2015.12.075

31. Kroenke K, Spitzer RL, Williams JB. The PHQ-9: validity of a brief depression severity measure. J Gen Intern Med. 2001;16(9):606-13. https://doi.org/ 10.1046/j.1525-1497.2001.016009606.x.

32. Wu X, Tao S, Zhang Y, et al. Geographic distribution of mental health problems among chinese college students during COVID-19 pandemic: cross-sectional, Online Survey Study [published online ahead of print, 2021 J Med Internet Res 2021;https://doi.org/10.2196/23126.

33. Ni MY, Yang L, Leung C, Li N, Yao XI, Wang Y, et al. Mental health, risk factors, and social media use during the COVID-19 epidemic and cordon sanitaire among the community and health professionals in Wuhan, China: cross-sectional survey. JMIR Mental Health. 2020;7(5):e19009. https://doi.org/10.2196/19009.

34. Main A, Zhou Q, Ma Y, Luecken LJ, Liu X. Relations of SARS-related stressors and coping to Chinese college students' psychological adjustment during the 2003 Beijing SARS epidemic. J Couns Psychol. 2011;58(3):41023. https://doi.org/10.1037/a0023632

35. Ghrouz AK.; Noohu MM.' Dilshad MM.; Warren SD.; Ba Hammam AS. Pandi-Perumal SR. Physical activity and sleep quality in relation to mental health among college students. Sleep Breath, 2019. 23(2), 627-634. doi: https://doi.org/10.1007/s11325-019-01780-z 
36. Talevi D, Socci V, Carai M, Carnaghi G, Faleri S, Trebbi E, et al. Mental health outcomes of the CoViD-19 pandemic. Riv Psichiatr. 2020;55(3):137-44. https://doi.org/10.1708/3382.33569.

37. Feng Q, Zhang QL, Du Y, Ye YL, He QQ. Associations of physical activity, screen time with depression, anxiety and sleep quality among Chinese college freshmen. PLoS One. 2014;9(6):e100914. Published 2014 Jun 25. https://doi.org/10.1371/journal.pone.0100914.

38. Hrafnkelsdottir SM, Brychta RJ, Rognvaldsdottir V, Gestsdottir S, Chen $K Y$, Johannsson $E$, et al. Less screen time and more frequent vigorous physical activity is associated with lower risk of reporting negative mental health symptoms among Icelandic adolescents. PLoS One. 2018;13(4):e0196286. https://doi.org/10.1371/journal.pone.0196286.

39. Huang Y, Wang Y, Wang H, Liu Z, Yu X, Yan J, et al. Prevalence of mental disorders in China: a cross-sectional epidemiological study. Lancet Psychiatry. 2019;6(3):211-24. https://doi.org/10.1016/S2215-0366(18) 30511-X Erratum in: Lancet Psychiatry. 2019; 6(4):e11. PMID: 30792114

40. Hawryluck L, Gold WL, Robinson S, Pogorski S, Galea S, Styra R. SARS control and psychological effects of quarantine, Toronto, Canada. Emerg Infect Dis. 2004;10(7):1206-12. https://doi.org/10.3201/eid1007.030703.

41. Sprang G, Silman M. Posttraumatic stress disorder in parents and youth after health-related disasters. Disaster Med Public Health Prep. 2013;7(1):105-10. https://doi.org/10.1017/dmp.2013.22.

42. Maisonnette $S$, Morato $S$, Brandão ML. Role of resocialization and of 5-HT1A receptor activation on the anxiogenic effects induced by isolation in the elevated plus-maze test. Physiol Behav. 1993 Oct;54(4):753-8. https://doi.org/10.1016/0031-9384(93)90087-v.

43. Morley BJ, Worsham E. The effects of prolonged handling, scopolamine, and physostigmine on the activity of isolated and socially reared rats. Physiol Psychol. 1978;6:83-8

44. Ikemoto S, Panksepp J. The effects of early social isolation on the motivation for social play in juvenile rats. Dev Psychobiol. 1992;25:261-74. https://doi.org/10.1002/dev.420250404.

45. McCool BA, Chappell AM. Early social isolation in male Long-Evans rats alters both appetitive and consummatory behaviors expressed during operant ethanol self-administration. Alcohol Clin Exp Res. 2009;33(2):27382. https://doi.org/10.1111/j.1530-0277.2008.00830.x

46. Orben A, Tomova L, Blakemore SJ. The effects of social deprivation on adolescent development and mental health. Lancet Child Adolesc Health. 2020;4(8):634-40. https://doi.org/10.1016/S2352-4642(20)30186-3.

47. Lim GY, Tam WW, Lu Y, Ho CS, Zhang MW, Ho RC. Prevalence of depression in the community from 30 countries between 1994 and 2014. Sci Rep. 2018:8(1):2861. https://doi.org/10.1038/s41598-018-21243-x.

48. Qiu J, Shen B, Zhao M, Wang Z, Xie B, Xu Y. A nationwide survey of psychological distress among Chinese people in the COVID-19 epidemic: implications and policy recommendations. Gen Psychiatr. 2020;33(2):e100213. https://doi.org/10.1136/gpsych-2020-100213 Erratum in: Gen Psychiatr. 2020 Apr 27;33(2):e100213corr1.

49. Lissak G. Adverse physiological and psychological effects of screen time on children and adolescents: Literature review and case study. Environ Res. 2018;164:149-57. https://doi.org/10.1016/j.envres.2018.01.015.

50. Twenge JM, Campbell WK. Associations between screen time and lower psychological well-being among children and adolescents: evidence from a population-based study. Prev Med Rep. 2018;12:271-83. https:// doi.org/10.1016/j.pmedr.2018.10.003.

51. Chao M, Xue D, Liu T, Yang H, Hall BJ. Media use and acute psychological outcomes during COVID-19 outbreak in China. J Anxiety Disord. 2020;74:102248. https://doi.org/10.1016/j.janxdis.2020.102248.

52. Resnyansky L. Social media, disaster studies, and human communication. IEEE Technol Soc Mag. 2014;33(1):54-65. https://doi.org/10.1109/MTS 2014.2301857.

53. Holman EA, Garfin DR, Silver RC. Media's role in broadcasting acute stress following the Boston Marathon bombings. Proc Natl Acad Sci U S A 2014;111(1):93-8. https://doi.org/10.1073/pnas.1316265110.

54. Dubey S, Biswas P, Ghosh R, Chatterjee S, Dubey MJ, Chatterjee S, et al. Psychosocial impact of COVID-19. Diabetes Metab Syndr. 2020;14(5):77988. https://doi.org/10.1016/j.dsx.2020.05.035

55. Liu M, Ming Q, Yi J, Wang X, Yao S. Screen time on school days and risks for psychiatric symptoms and self-harm in mainland Chinese adolescents. Front Psychol. 2016;7:574. https://doi.org/10.3389/fpsyg.2016. 00574.
56. Lachlan KA, Spence PR, Seeger M. Terrorist attacks and uncertainty reduction: Media use after September 11. Behav Sci Terror Polit Aggression. 2009;1 (2):101-10. https://doi.org/10.1080/19434470902771683.

57. Burke M, Marlow C, Lento T. Social network activity and social wellbeing. CHI'10: Proceedings of the SIGCHI conference on human factors in computing systems. Atlanta: ACM Press; 2010. p. 1909-12.

58. O'Donovan G, Blazevich AJ, Boreham C, Cooper AR, Crank H, Ekelund $U$, et al. The $A B C$ of physical activity for health: a consensus statement from the British Association of Sport and Exercise Sciences. J Sports Sci. 2010;28(6):573-91. https://doi.org/10.1080/02640411003671212.

59. Crisafulli A, Pagliaro P. Physical activity/inactivity and COVID-19. Eur J Prev Cardiol. 2020;18:2047487320927597. https://doi.org/10.1177/ 2047487320927597.

60. Rocha SF, Marocolo M, Corrêa EN, Morato GS, da Mota GR. Physical activity helps to control music performance anxiety. Med Probl Perform Art. 2014:29(2):111-2. https://doi.org/10.21091/mppa.2014.2022.

61. Adams TB, Moore MT, Dye J. The relationship between physical activity and mental health in a national sample of college females. Women Health. 2007;45(1):69-85. https://doi.org/10.1300/J013v45n01_05.

62. Jiménez-Pavón D, Carbonell-Baeza A, Lavie CJ. Physical exercise as therapy to fight against the mental and physical consequences of COVID-19 quarantine: Special focus in older people. Prog Cardiovasc Dis. 2020;63(3):386-8. https://doi.org/10.1016/j.pcad.2020.03.009.

63. Lippi G, Henry BM, Sanchis-Gomar F. Physical inactivity and cardiovascular disease at the time of coronavirus disease 2019 (COVID-19). Eur J Prev Cardiol. 2020;27(9):906-8. https://doi.org/10.1177/2047487320 916823.

64. Rothon C, Edwards P, Bhui K, Viner RM, Taylor S, Stansfeld SA. Physical activity and depressive symptoms in adolescents: a prospective study. BMC Med. 2010;8:32. https://doi.org/10.1186/1741-7015-8-32.

65. Cao H, Qian Q, Weng T, Yuan C, Sun Y, Wang H, et al. Screen time, physical activity and mental health among urban adolescents in China. Prev Med. 2011;53(4-5):316-20. https://doi.org/10.1016/j.ypmed.2011.09.002.

66. Kremer P, Elshaug C, Leslie E, Toumbourou JW, Patton GC, Williams J. Physical activity, leisure-time screen use and depression among children and young adolescents. J Sci Med Sport. 2014;17(2):183-7. https://doi. org/10.1016/j.jsams.2013.03.012

67. Trinh L, Wong B, Faulkner GE. The independent and interactive associations of screen time and physical activity on mental health, school connectedness and academic achievement among a population-based sample of youth. J Can Acad Child Adolesc Psychiatry. 2015;24(1):17-24.

68. Vallance JK, Winkler EA, Gardiner PA, Healy GN, Lynch BM, Owen N. Associations of objectively-assessed physical activity and sedentary time with depression: NHANES (2005-2006). Prev Med. 2011;53(4-5):284-8. https:// doi.org/10.1016/j.ypmed.2011.07.013.

69. Teychenne M, Ball K, Salmon J. Physical activity and likelihood of depression in adults: a review. Prev Med. 2008;46(5):397-411. https://doi.org/10. 1016/j.ypmed.2008.01.009.

70. Ströhle A. Physical activity, exercise, depression and anxiety disorders. J Neural Transm (Vienna). 2009;116(6):777-84. https://doi.org/10.1007/ s00702-008-0092-x

71. Dunn AL, Trivedi MH, O'Neal HA. Physical activity dose-response effects on outcomes of depression and anxiety. Med Sci Sports Exerc. 2001:33(6 Suppl):S587-610. https://doi.org/10.1097/00005768-200106001-00027.

72. Wicke T, Silver RC. A community responds to collective trauma: An ecological analysis of the James Byrd murder in Jasper, Texas. Am J Community Psychol. 2009;44(3-4):233-48. https://doi.org/10.1007/ s10464-009-9262-8.

73. Janssen I. Estimating whether replacing time in active outdoor play and sedentary video games with active video games influences youth's mental health. J Adolesc Health. 2016;59(5):517-22.

74. Tremblay MS, LeBlanc AG, Kho ME, Saunders TJ, Larouche R, Colley RC, et al. Systematic review of sedentary behaviour and health indicators in school-aged children and youth. Int J Behav Nutr Phys Act. 2011;8:98.

75. Wu X, Tao S, Rutayisire E, Chen Y, Huang K, Tao F. The relationship between screen time, nighttime sleep duration, and behavioural problems in preschool children in China. Eur Child Adolesc Psychiatry. 2017;26:541-8.

76. Oswald TK, Rumbold AR, Kedzior S, Moore VM. Psychological impacts of "screen time" and "green time" for children and adolescents: a systematic scoping review. PLoS One. 2020;15(9):e0237725. 
77. Marques A, Calmeiro L, Loureiro N, Frasquilho D, de Matos MG. Health complaints among adolescents: Associations with more screen-based behaviours and less physical activity. J Adolesc. 2015;44:150-7.

78. Bélanger M, Gallant F, Doré I, O'Loughlin JL, Sylvestre MP, Abi Nader P, et al. Physical activity mediates the relationship between outdoor time and mental health. Prev Med Rep. 2019;16:101006.

79. de Graaff AM, Cuijpers P, Acarturk C, Bryant R, Burchert S, Fuhr DC, et al. Effectiveness of a peer-refugee delivered psychological intervention to reduce psychological distress among adult Syrian refugees in the Netherlands: study protocol. Eur J Psychotraumatol. 2020;11(1):1694347-10.1080/20008198.2019.1694347.

80. Zhou X. Psychological crisis interventions in Sichuan Province during the 2019 novel coronavirus outbreak. Psychiatry Res. 2020;286:112895. https://doi.org/10.1016/j.psychres.2020.112895.

81. Duan L, Zhu G. Psychological interventions for people affected by the COVID-19 epidemic. Lancet Psychiatry. 2020;7(4):300-2. https://doi.org/ 10.1016/S2215-0366(20)30073-0.

82. Peluso MA, Guerra de Andrade LH. Physical activity and mental health: the association between exercise and mood. Clinics. 2005b;60(1):61-70. https://doi.org/10.1590/s1807-59322005000100012.
83. Hammami A, Harrabi B, Mohr M, Krustrup P. Physical activity and coronavirus disease 2019 (COVID-19): specific recommendations for homebased physical training. Manag Sport Leis. 2020:1-6. https://doi.org/10. 1080/23750472.2020.1757494.

84. Hinkley T, Brown H, Carson V, Teychenne M. Cross sectional associations of screen time and outdoor play with social skills in preschool children. PLoS One. 2018;13(4):e0193700.

85. Zhang X, Li M, Guo L, Zhu Y. Mental health and its influencing factors among left-behind children in South China: a cross-sectional study. BMC Public Health. 2019;19(1):1725.

\section{Publisher's Note}

Springer Nature remains neutral with regard to jurisdictional claims in published maps and institutional affiliations.
Ready to submit your research? Choose BMC and benefit from:

- fast, convenient online submission

- thorough peer review by experienced researchers in your field

- rapid publication on acceptance

- support for research data, including large and complex data types

- gold Open Access which fosters wider collaboration and increased citations

- maximum visibility for your research: over $100 \mathrm{M}$ website views per year

At BMC, research is always in progress.

Learn more biomedcentral.com/submissions 